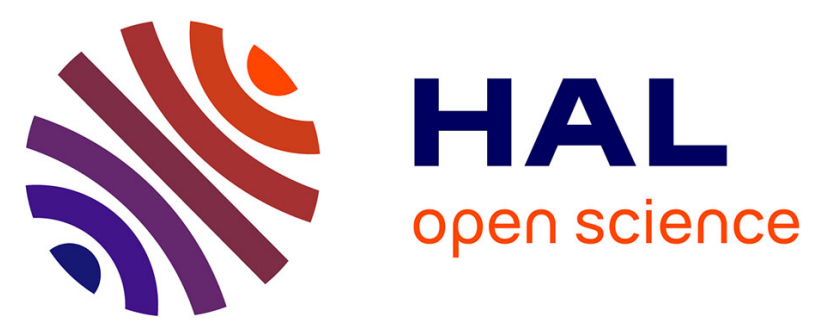

\title{
Dispersed Ni nanoparticles stabilize silicon photoanodes for efficient and inexpensive sunlight-assisted water oxidation
}

Gabriel Loget, Bruno Fabre, Stephanie Fryars, Cristelle Mériadec, Soraya

Ababou-Girard

\section{To cite this version:}

Gabriel Loget, Bruno Fabre, Stephanie Fryars, Cristelle Mériadec, Soraya Ababou-Girard. Dispersed Ni nanoparticles stabilize silicon photoanodes for efficient and inexpensive sunlight-assisted water oxidation. ACS Energy Letters, 2017, 2 (3), pp.569-573. 10.1021/acsenergylett.7b00034 . hal01517483

\section{HAL Id: hal-01517483 \\ https://hal-univ-rennes1.archives-ouvertes.fr/hal-01517483}

Submitted on 4 Jul 2017

HAL is a multi-disciplinary open access archive for the deposit and dissemination of scientific research documents, whether they are published or not. The documents may come from teaching and research institutions in France or abroad, or from public or private research centers.
L'archive ouverte pluridisciplinaire HAL, est destinée au dépôt et à la diffusion de documents scientifiques de niveau recherche, publiés ou non, émanant des établissements d'enseignement et de recherche français ou étrangers, des laboratoires publics ou privés. 


\section{Dispersed Ni Nanoparticles Stabilize Silicon}

\section{Photoanodes for Efficient and Inexpensive Sunlight-}

\section{Assisted Water Oxidation}

Gabriel Loget, ${ }^{*}{ }^{\dagger}$ Bruno Fabre, ${ }^{\dagger}$ Stéphanie Fryars, ${ }^{\dagger}$ Cristelle Meriadec, ${ }^{\dagger}$ and Soraya Ababou-

Girard

† Institut des Sciences Chimiques de Rennes, UMR 6226 CNRS, Matière Condensée et Systèmes

Electroactifs (MaCSE), and

\$Institut de Physique de Rennes, UMR 6251 CNRS, Equipe de Physique des Surfaces et

Interfaces, Université de Rennes 1, Campus de Beaulieu, 35042 Rennes Cedex, France

\section{Corresponding Author}

* gabriel.loget@univ-rennes1.fr 


\begin{abstract}
$\mathrm{Ni}$, electrodeposited on $n$-type $\mathrm{Si}$ from aqueous solutions, in the form of isolated or coalescent nanoparticles (NPs) protects the underlying and partially exposed Si from photocorrosioninduced electrical passivation. Such photoanodes, fabricated without the need of additional protecting layers, buried junction and high vacuum techniques, show a high photovoltage of $\approx 500 \mathrm{mV}$ for the oxygen evolution reaction (OER), state-of-the-art photocurrents and faradaic efficiencies $>90 \%$ under AM 1.5G illumination conditions at $\mathrm{pH} 14$. Remarkably, these photoelectrodes are stable and can be operated at the light-limited catalytic current from $10 \mathrm{~h}$ to more than $40 \mathrm{~h}$ in $1 \mathrm{M} \mathrm{NaOH}$. These findings demonstrate that robust and efficient Si-based photoanodes can be produced easily, which opens new opportunities for the implementation of low-cost Si-based monolithic photoelectrochemical cells for efficient solar fuel production.
\end{abstract}

TOC GRAPHICS

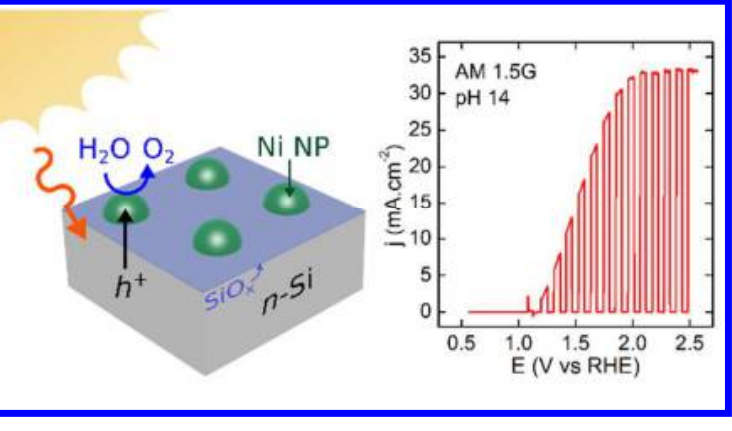


Carbon-free chemical fuels that can be produced from renewable sources are highly promising energy vectors, essential for the development of a sustainable energy economy. ${ }^{1}$ In this frame, $\mathrm{H}_{2}$ is of particular interest because it provides a high energy density, it can be easily stored, transported and readily used to power electrical devices. Alike photosynthesis, where photons are converted into energy-rich molecules, sunlight energy can be converted in $\mathrm{H}_{2}$ and $\mathrm{O}_{2}$ using photoelectrochemical water splitting cells (PECs), that are currently attracting tremendous research efforts. ${ }^{2-7}$ Monolithic PECs are generally composed of a $p$-type semiconductor ( $p$-SC) and an $n$-type SC (n-SC) that are in intimate contact and immersed in an aqueous solution. Upon sunlight absorption, photogenerated charge carriers are driven to the solid-liquid interface where they react with water. ${ }^{2-7}$ Electrons generated in the $p$-SC reduce water to $\mathrm{H}_{2}$ while holes, generated in the $n$-SC, oxidize water to $\mathrm{O}_{2}$ simultaneously. Silicon is considered as one of the most attractive materials for manufacturing PEC photoelectrodes because of its abundance and its wide use in microelectronic and photovoltaic industries. ${ }^{8}$ Moreover, it conveniently has a high carrier mobility, a suitable electronic structure and an optimal band gap that allows absorbing all the solar spectrum. ${ }^{8}$ Nevertheless, using $\mathrm{Si}$ as a photoanode material is very challenging mainly because of two reasons: $i$ ) water oxidation is a four-electron process, which is sluggish at $\mathrm{Si}$ surface and requires a substantial overpotential to occur and $i$ ) Si is highly prone to photocorrosion, and its oxidation to insulating $\mathrm{SiO}_{\mathrm{x}}$ is the main process arising under anodic polarization. ${ }^{8-10}$ The latter phenomenon is strongly pronounced in alkaline media, and induces the quasi-spontaneous passivation of Si photoanodes when used for water splitting. This technological issue had remained a deadlock for the development of Si monolithic PECs for the last decades. Recently, tremendous progress has been made by employing thin film deposition techniques such as physical vapor deposition (PVD) and atomic layer deposition (ALD) for 
coating Si with conformal single or multiple thin films that serve as protecting and/or catalytic layers. ${ }^{8-11} \mathrm{Ni}$ and $\mathrm{NiO}_{\mathrm{x}}$ are excellent coating materials as they provide corrosion resistance and a high catalytic activity for the oxygen evolution reaction (OER) at high $\mathrm{pH}$ (see table $\mathrm{S} 1) .{ }^{12,13} \mathrm{In}$ particular, Kenney et al. have firstly reported that e-beam evaporated thin Ni layers protect Si photoanodes. ${ }^{14}$ Following this work, Ni-based alloys and oxides, sputtered on $n$-Si ${ }^{15}$ and $n p^{+}$$\mathrm{Si}^{16-18}$ junctions have demonstrated high performances for OER. Notably, Lewis' team has demonstrated that layers of $\mathrm{Ni}^{19}$ and $\mathrm{NiCrO}_{\mathrm{x}},{ }^{20}$ sputtered on $\mathrm{TiO}_{2}$-protected planar and microstructured $n p^{+}-\mathrm{Si}$ junctions, were stable for periods of $100 \mathrm{~h}^{19}$ and $2200 \mathrm{~h},{ }^{20}$ respectively, in strongly alkaline media. Furthermore, a reactive sputter method has been developed for coating Si surfaces with transparent $\mathrm{NiO}_{\mathrm{x}}$ layers, ${ }^{21}$ that protect $\mathrm{Si}$-based photoelectrodes for prolonged water splitting. ${ }^{22}$ If these works constitute major breakthroughs for the implementation of efficient and stable Si-based PECs, they all share the use of high vacuum techniques for the layer deposition. Alternatives to sputtering and ALD would be interesting from a financial point of view but also because they would open exciting possibilities in terms of layer composition and morphologies. In this context, $\mathrm{NiO}_{\mathrm{x}}$ layers, deposited by a sol-gel method on $n$-Si have a catalytic activity towards OER at neutral ${ }^{23}$ and alkaline $\mathrm{pH} \cdot{ }^{24}$ Although electrodeposition has been not much explored for this application so far, it is very attractive since it can be easily implemented and it allows a precise control over the coating morphology. In this context, Nocera et al. have reported the use of electrodeposited Co-based catalysts, operating at neutral $\mathrm{pH}$ on $\mathrm{Si}^{25}$ Lately, Switzer's group has shown that inhomogeneous Co particles, electrodeposited on $n$ Si surfaces allow to perform OER for $2 \mathrm{~h}$ at high $\mathrm{pH}$ and it has been very recently reported that $\mathrm{NiFe}$ electrodeposited on $n p^{+}-\mathrm{Si}$ is highly effective for OER.$^{27}$ High interest is currently being given to the understanding of Si interfaces coated with inhomogeneous co-catalysts layers. In 


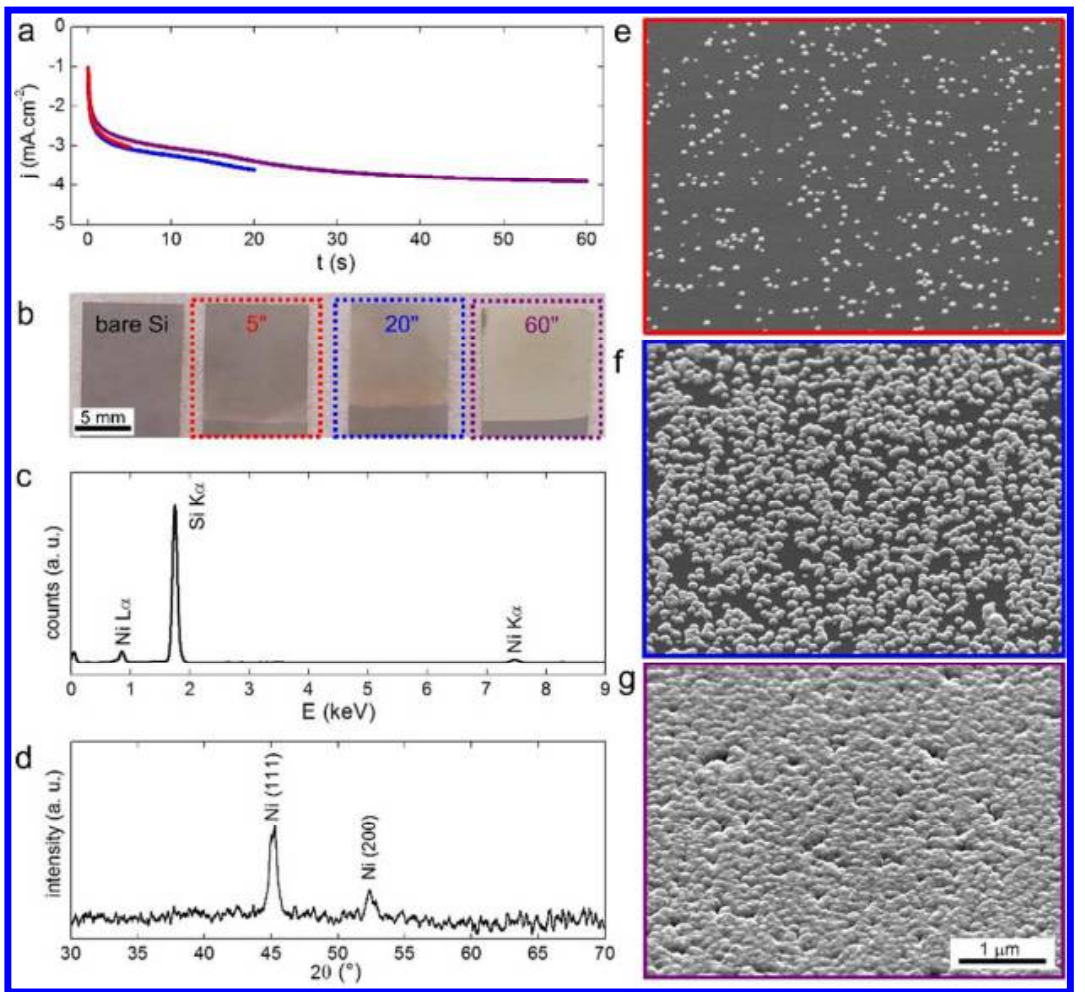

Figure 1. Characterization of the Ni-decorated surfaces. a) Chronoamperograms for $\mathrm{Ni}$ electrodeposition on hydrogenated $n$-Si. b) Photographs of bare and Ni-coated $n$-Si. c) EDS and d) XRD spectra of Ni-coated $n$-Si. e-g) SEM pictures showing the Ni deposits on $n$-Si (the 
surfaces were tilted by $45^{\circ}$ ). In these panels, data depicted or framed in red, blue and purple correspond to the surfaces obtained for electrodeposition times of $5 \mathrm{~s}, 20 \mathrm{~s}$ and $60 \mathrm{~s}$, respectively.

In this work, $\mathrm{Ni}$ was deposited at $-1.5 \mathrm{~V}$ vs KCl-saturated calomel electrode (SCE) on freshly hydrogenated $n$-Si (100) from an aqueous solution containing Ni chloride and boric acid. The potentiostatic method allows to conveniently control the amount of deposited material as well as the morphology of the layer over time. Indeed, the chronoamperograms of Fig. 1a reveal the evolution of the electrodeposition kinetics and show that the current density $j$ decreased sharply before stabilizing. This is consistent with the formation of nuclei that grow and reach coalescence. The resulting coatings were homogeneous and could be observed with the naked eye (Fig. 1b). Energy-dispersive X-ray spectroscopy (EDS) and X-ray diffraction (XRD) measurements confirmed the presence of crystalline Ni on Si (Fig. 1c and 1d). Scanning electron microscopy (SEM) images, shown in Fig. 1e-g (and Fig S1-3) indicated that 5 s electrodeposition led to a film of randomly-dispersed Ni nanoparticles (Ni NPs) having a mean diameter of $59 \pm 17$ nm (Fig. S4). At $20 \mathrm{~s}$, the Ni NPs grew further and the majority started to merge, creating NP aggregates having a projected area in the range of $0.05 \mu \mathrm{m}^{2}$, while at $60 \mathrm{~s}$ they all coalesced, yielding a deposit that can be considered as a film with a thickness of $68 \pm 11 \mathrm{~nm}$ (Fig. S1d).The photoelectrochemical performances of the so-fabricated surfaces were then tested in $1 \mathrm{M} \mathrm{NaOH}$ (measured $\mathrm{pH}=14)$, using simulated sunlight $\left(\mathrm{AM} 1.5 \mathrm{G}, 100 \mathrm{~mW} \mathrm{~cm}^{-2}\right.$ ). First, we verified by cyclic voltammetry $(\mathrm{CV})$ that uncoated $n$-Si quickly passivated under these experimental conditions, due to photocorrosion (Fig. S5). Before any experiments, the Ni-coated photoelectrodes were cycled by performing several CV scans under illumination (typically, $<40$ ) until they reached a stable photocurrent curve (see Supporting Information and Fig. S8). Fig. 2 shows the CVs obtained for the coated Si surfaces, under illumination for $n$-Si and in the dark for 
$n$ - and $p^{++}-\mathrm{Si}$ (note that the potential scale versus reversible hydrogen electrode (RHE), is plotted on the top of Fig. 2). In this work, unless specified, the cell resistance was intentionally uncompensated. In the dark, all currents were negligible (in the range of $1 \mu \mathrm{A} \mathrm{cm}^{-2}$ ), except for Ni-coated $p^{++}-\mathrm{Si}$ that is essentially behaving as a metal. In contrast, photocurrents densities in the $\mathrm{mA} \mathrm{cm}{ }^{-2}$ range were measured for Ni-coated $n$-Si under illumination.

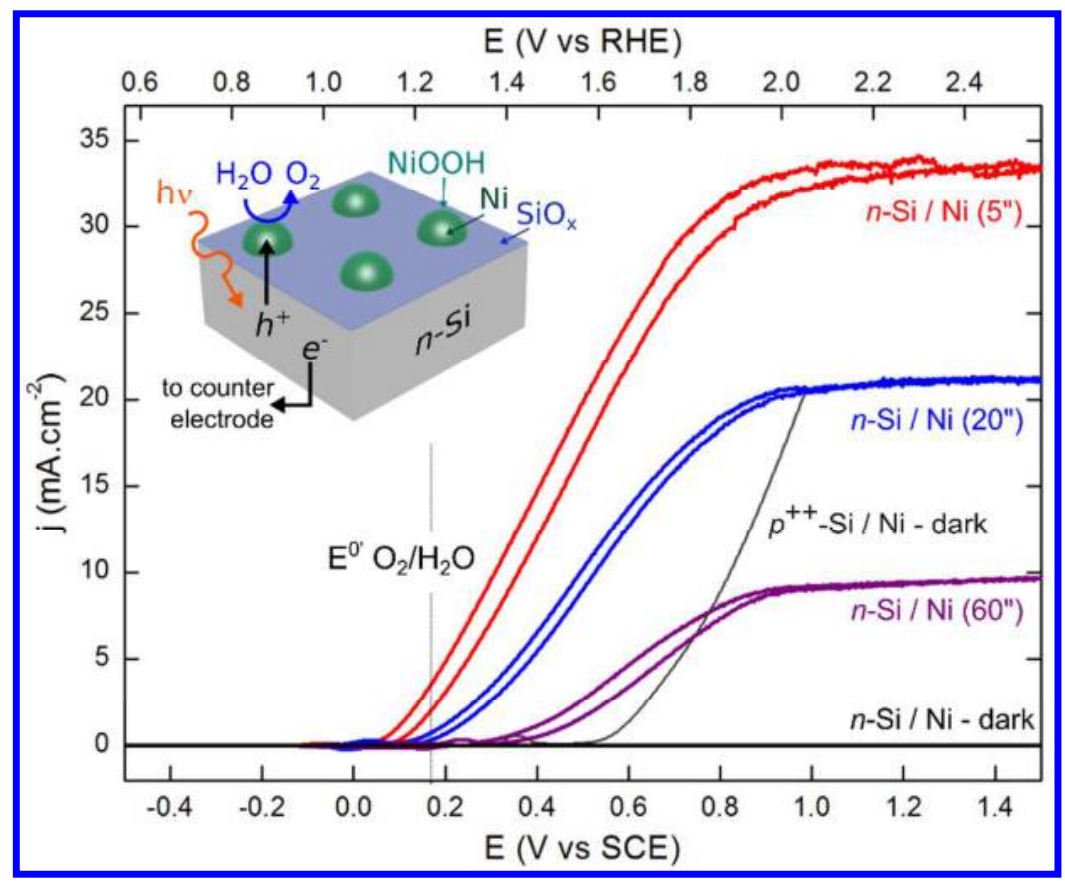

Figure 2. Photoelectrochemical water oxidation. CVs measured in the dark for $n$-Si decorated with Ni NPs (thick black line) and $p^{++}-\mathrm{Si}$ coated with Ni (thin black line) and under illumination (AM 1.5G, $100 \mathrm{~mW} \mathrm{~cm}^{-2}$ ) for $n$-Si coated with Ni for $5 \mathrm{~s}$ (red line), $20 \mathrm{~s}$ (blue line) and $60 \mathrm{~s}$ (purple line); all the curves were recorded in $1 \mathrm{M} \mathrm{NaOH}$ at a sweep rate of $20 \mathrm{mV} \mathrm{s}^{-1}$. Inset: scheme of the surface under illumination.

In all cases, a scan rate-dependent reversible redox wave $\left(\mathrm{Ni}^{3+} / \mathrm{Ni}^{2+}\right)$ was first observed, corresponding to the oxidation of $\mathrm{Ni}$ hydroxide to $\mathrm{NiOOH}$ (Fig. S6 and Fig. S11), generated at the Ni NP-electrolyte interface upon immersion in the alkaline solution and during the 
electrochemical cycling (note that $\mathrm{NiOOH}$ is the catalytically active species for OER). ${ }^{12,29}$ The determination of the charge under the oxidation peak (shown in Fig. S11 for an electrodeposition time of $5 \mathrm{~s}$ ), as compared with the NP density and average diameter (Fig. S4), allowed to estimate that about one fifth of the $\mathrm{Ni}$ atoms were catalytically-active. This wave was followed, at potential $\sim 100 \mathrm{mV}$ more positive than its cathodic peak $\left(E_{\mathrm{pc}}\right)$, by the much larger OER photocurrent. Table S2 gathers the photoelectrochemical parameters as a function of the doping type and the Ni amount. From these data, it can be clearly observed that every $n$-Si photoanode exhibited a negative shift of onset potential with respect to the Ni-coated $p^{++}-\mathrm{Si}$ anode. The photovoltage and the maximum photocurrent density $j_{\max }$ were clearly Ni-dependent and increased with a decreasing amount of electrodeposited Ni. As it can be seen in Fig. 2 and Fig S15, the decoration with isolated Ni NPs (Fig. 1e) provided the highest photovoltage and photocurrent density. This photovoltage of $0.5 \mathrm{~V}$ is very close to the one reported for conformal ultrathin Ni coatings prepared by e-beam evaporation on $n$-Si photoanodes without buried junctions. ${ }^{14}$ The photocurrent of $33 \mathrm{~mA} \mathrm{~cm}^{-2}$ is in the same range than the one obtained for sputtered Ni-based coatings on $n p^{+}$-Si junctions ${ }^{21,22}$ and electrodeposited Co on $n$-Si at comparable $\mathrm{pH}^{26}$ The flatband potentials $\left(E_{f b}\right)$ were comprised between -0.55 and $-0.60 \mathrm{~V}$ vs SCE (Fig S7), which is also in good agreement with the values reported for sputtered Ni films. ${ }^{14}$ The best electrode generated a photocurrent density of $3.5 \mathrm{~mA} \mathrm{~cm}$ at the $\mathrm{O}_{2} / \mathrm{H}_{2} \mathrm{O}$ formal potential, corresponding to $16.5 \mathrm{~mA} \mathrm{~cm}^{-2}$ when the cell resistance was compensated, as shown in Fig. S16. The stability of the photoanodes was then evaluated by chronoamperometry (CA) at +1 V vs SCE in the same conditions during a prolonged time. Fig. 3a shows the photocurrent evolution over time for the three different coatings. First, we note that all photocurrents obtained in these experiments were very close to those previously observed in the CVs of Fig. 2. All the 
photoanodes maintained at least $70 \%$ of their initial $j_{\max }$ over periods longer than $10 \mathrm{~h}$, which is much higher than the durations previously reported at this $\mathrm{pH}$ for coatings electrodeposited on $n$ Si surfaces (Table $\mathrm{S} 1)^{25,26}$

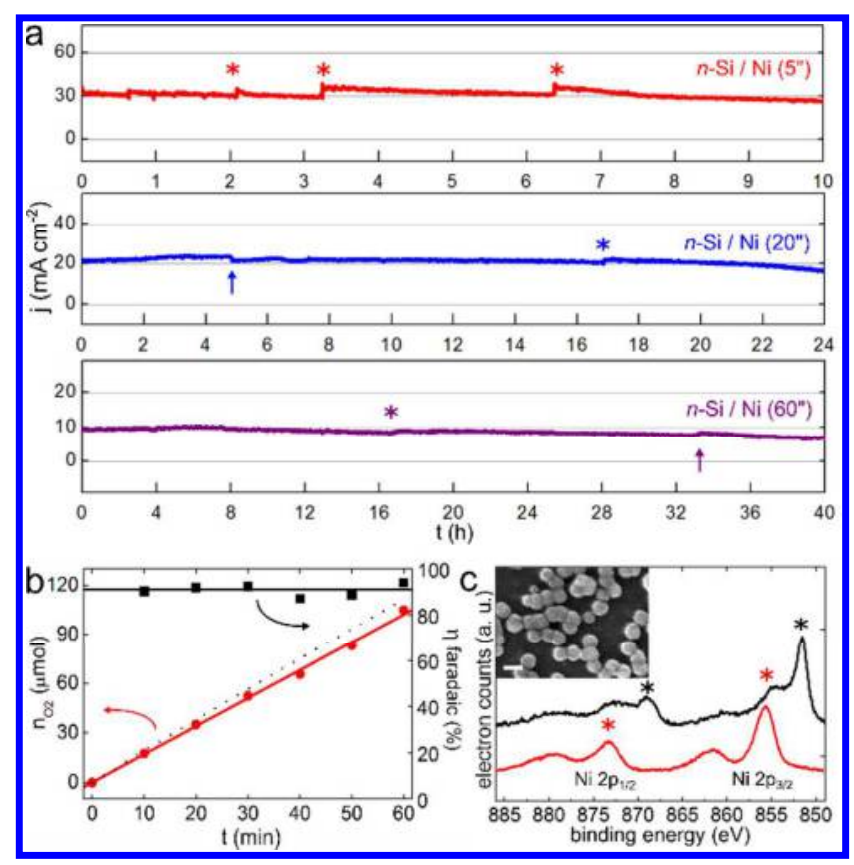

Figure 3. Stability and faradaic efficiency of the photoanodes. a) CAs obtained during prolonged photoelectrolysis in $1 \mathrm{M} \mathrm{NaOH}$ under AM 1.5G illumination at $+1 \mathrm{~V}$ vs SCE for $n$-Si surfaces coated with Ni that was electrodeposited for $5 \mathrm{~s}$ (red), $20 \mathrm{~s}$ (blue) and $60 \mathrm{~s}$ (purple). The asterisks indicate when bubbles were removed from the surface, arrows indicate when the electrolysis was stopped and the photoelectrodes were dried and stored overnight. b) Number of moles of $\mathrm{O}_{2}$ produced (red disks are experimental data and the red line is a linear fit) during a preparative electrolysis at $+1 \mathrm{~V}$ vs SCE using a $n$-Si surface coated with Ni for $5 \mathrm{~s}$ (see SI for more details). The black dotted line is the theoretical amount of $\mathrm{O}_{2}$, the black squares and the black line are the faradaic efficiencies and its average value, respectively. c) XPS spectra of the Ni $2 p$ region for the $n$-Si surface coated with $\mathrm{Ni}$ for $20 \mathrm{~s}$; after preparation (black line) and after $\approx 25 \mathrm{~h}$ of electrolysis (red line). The black asterisks indicate $\mathrm{Ni}^{0}$ peaks and the red asterisks indicate $\mathrm{Ni}$ 
oxides peaks (more information on the spectra is provided in the SI). Inset: SEM picture showing the corresponding surface after electrolysis, the scale bar corresponds to $100 \mathrm{~nm}$.

These data clearly demonstrate that our photoanodes are particularly robust, even if the Ni deposits are not conformal. This is also shown by the fact that they maintained their activity after being stored in air (ambient conditions) overnight when the electrolysis was stopped. Such a stability was unexpected because, in the case of our best-performing photoanodes, most of the $\mathrm{Si}$ is in contact with the solution and therefore passivated with a $\mathrm{SiO}_{\mathrm{x}}$ layer. X-ray photoelectron spectroscopy (XPS), confirmed the presence of oxygen on the freshly prepared surface and its significant increase after electrolysis (Fig. S13), suggesting that the Si surface is initially covered by $\mathrm{a} \mathrm{SiO}_{\mathrm{x}}$ layer that grows during the anodic polarization. Therefore, the photocatalytic performances and the stability seem related to the generation of an effective inhomogeneous metal-insulator-semiconductor (MIS) structure $\left(\mathrm{Ni}-\mathrm{SiO}_{\mathrm{x}}-\mathrm{Si}\right) .{ }^{8,26}$ Interestingly, we clearly observe that the stability is enhanced with an increasing amount of $\mathrm{Ni}$, showing that thicker and denser Ni coatings decrease the photocorrosion kinetics by protecting underlying Si from the oxidative solution. However, the stability is increased at the expense of the photocurrent density and photovoltage (Table S2). Like previously reported for electrodeposited discontinuous Co films ${ }^{26}$ and evaporated Ni layers behaving as inhomogeneous buried junctions, ${ }^{28}$ thicker catalytic layers led, in our case, to weaker light-limited photocurrents and photovoltages.

Gas chromatography (GC) confirmed that the produced gas was $\mathrm{O}_{2}$. The best photoanode configuration ( 5 s electrodeposition) was tested by additional electrolyses in a Hoffman cell, which allowed measuring the volume of produced $\mathrm{O}_{2}$ (see the SI for details). Fig. $3 \mathrm{~b}$ shows that the photoelectrode produced $\mathrm{O}_{2}$ at a rate of $4.5 \mu \mathrm{mol} \mathrm{min} \mathrm{m}^{-1} \mathrm{~cm}^{-2}$, which corresponds to a faradaic 
efficiency higher than $>90 \%$, this was also confirmed by another set of experiments described in the supporting information (see the SI and Fig. S10). Based on the amount of $\mathrm{O}_{2}$ produced in Fig. $3 \mathrm{~b}$ and the number of active $\mathrm{Ni}$ sites determined by measuring the charge under the $\mathrm{Ni}^{3+} / \mathrm{Ni}^{2+}$ wave of the CV (shown in Fig. S11), we calculated a turnover frequency (TOF) of $1.14 \times 10^{5} \mathrm{~h}^{-1}$ (see supporting information for more details). Most of the electrodeposited Ni was still present on the surface after $\approx 25 \mathrm{~h}$ of electrolysis, as shown by SEM and XPS (Fig. 3c and in Fig. S12), which demonstrates the robustness of the interaction between the Ni NPs and the Si surface.

In conclusion, we have demonstrated that $n$-Si surfaces coated with electrodeposited $\mathrm{Ni}$ can be used as efficient photoanodes with faradaic yields $>90 \%$ in strongly alkaline $\mathrm{pH}$. The best performances in terms of photovoltage, onset potential and photocurrent density are in the same range than the one reported for more complicated thin layer processes on $n$-Si (table $\mathrm{S} 1$ ) and were obtained for randomly-dispersed Ni NPs, which led to a stability of $10 \mathrm{~h}$ at the light-limited photocurrent density $\left(33 \mathrm{~mA} \mathrm{~cm}^{-2}\right)$. We have shown that stability can be extended to $40 \mathrm{~h}$ by increasing the amount of $\mathrm{Ni}$ on the surface, which is detrimental to the photovoltage and photocurrent. Moreover, we have demonstrated that Ni coverage can be finely controlled by electrodeposition, which makes it a powerful tool for tuning the photoelectrode activity. These results show that cheap and reliable photoanodes can be simply fabricated without the need of high vacuum techniques. We anticipate that the performances reported here will be soon further improved by employing surface texturing ${ }^{30}$ and buried $n p^{+}$junctions. Electrodeposition could be beneficially used to improve the electrode design, for instance, by tuning the morphology of the Ni nanocatalysts, additionally, these surfaces may be appealing structures for studying fundamental phenomena taking place at Si-based photoanodes. 


\title{
ASSOCIATED CONTENT
}

Supporting Information. The Supporting Information containing the experimental procedure and the supplementary figures and tables is available free of charge on the ACS Publications website.

\section{AUTHOR INFORMATION \\ gabriel.loget@univ-rennes1.fr}

\section{Notes}

The authors declare no competing financial interest.

\author{
ACKNOWLEDGMENT \\ This work is partly funded by ANR (project EASi-NANO, ANR-16-CE09-0001-01) and has also \\ been supported by Rennes Métropole (AIS 16C402). Cécile Valter-Potier is acknowledged for \\ the fabrication of the electrochemical cells. Francis Gouttefangeas and Loic Joanny (ScanMAT- \\ CMEBA, Univ. Rennes 1) are acknowledged for SEM imaging.
}

\section{REFERENCES}

(1) Lewis, N. S.; Nocera, D. G. Powering the Planet: Chemical Challenges in Solar Energy Utilization. Proc.Natl_Acad.Sci. 2006, 103, 15729-15735.

(2) Lewis, N. S. Developing a Scalable Artificial Photosynthesis Technology through Nanomaterials by Design. Nat. Nanotechnol. 2016, 11, 1010-1019.

(3) Walter, M. G.; Warren, E. L.; McKone, J. R.; Boettcher, S. W.; Mi, Q.; Santori, E. A.; Lewis, N. S. Solar Water Splitting Cells. Chem.Rev. 2010, 110, 6446-6473.

(4) Fujishima, A.; Honda, K. Electrochemical Photolysis of Water at a Semiconductor 
Electrode. Nature 1972, 238, 37-38.

(5) Prévot, M. S.; Sivula, K. Photoelectrochemical Tandem Cells for Solar Water Splitting. J. Phys. Chem. C 2013, 117, 17879-17893.

(6) Xiang, C.; Weber, A. Z.; Ardo, S.; Berger, A.; Chen, Y.; Coridan, R.; Fountaine, K. T.; Haussener, S.; Hu, S.; Liu, R.; et al. Modeling, Simulation, and Implementation of Solar-Driven Water-Splitting Devices. Angew. Chem. Int. Ed. 2016, 55, 12974-12988.

(7) Sivula, K.; van de Krol, R. Semiconducting Materials for Photoelectrochemical Energy Conversion. Nat. Rev. Mater. 2016, 1, 15010.

(8) Sun, K.; Shen, S.; Liang, Y.; Burrows, P. E.; Mao, S. S.; Wang, D. Enabling Silicon for Solar-Fuel Production. Chem. Rev. 2014, 114, 8662-8719.

(9) Xia, Z.; Zhou, X.; Li, J.; Qu, Y. Protection Strategy for Improved Catalytic Stability of Silicon Photoanodes for Water Oxidation. Sci. Bull. 2015, 60, 1395-1402.

(10) Hu, S.; Lewis, N. S.; Ager, J. W.; Yang, J.; McKone, J. R.; Strandwitz, N. C. Thin-Film Materials for the Protection of Semiconducting Photoelectrodes in Solar-Fuel Generators. $J$. Phys. Chem. C 2015, 119, 24201-24228.

(11) Scheuermann, A. G.; Lawrence, J. P.; Kemp, K. W.; Ito, T.; Walsh, A.; Chidsey, C. E. D.; Hurley, P. K.; McIntyre, P. C. Design Principles for Maximizing Photovoltage in MetalOxide-Protected Water-Splitting Photoanodes. Nat. Mater. 2016, 15, 99-105.

(12) Trotochaud, L.; Ranney, J. K.; Williams, K. N.; Boettcher, S. W. Solution-Cast Metal Oxide Thin Film Electrocatalysts for Oxygen Evolution. J. Am. Chem. Soc. 2012, 134, 1725317261.

(13) Hunter, B. M.; Gray, H. B.; Müller, A. M. Earth-Abundant Heterogeneous Water Oxidation Catalysts. Chem. Rev. 2016, 116, 14120-14136. 
(14) Kenney, M. J.; Gong, M.; Li, Y.; Wu, J. Z.; Feng, J.; Lanza, M.; Dai, H. High-

Performance Silicon Photoanodes Passivated with Ultrathin Nickel Films for Water Oxidation.

Science 2013, 342, 836-840.

(15) Sun, K.; Pang, X.; Shen, S.; Qian, X.; Cheung, J. S.; Wang, D. Metal Oxide Composite

Enabled Nanotextured Si Photoanode for Efficient Solar Driven Water Oxidation. Nano Lett.

2013, 13, 2064-2072.

(16) Chen, L.; Yang, J.; Klaus, S.; Lee, L. J.; Woods-Robinson, R.; Ma, J.; Lum, Y.; Cooper,

J. K.; Toma, F. M.; Wang, L.-W.; et al. p-Type Transparent Conducting Oxide/n-Type

Semiconductor Heterojunctions for Efficient and Stable Solar Water Oxidation. J. Am. Chem.

Soc. 2015, 137, 9595-9603.

(17) Bae, D.; Mei, B.; Frydendal, R.; Pedersen, T.; Seger, B.; Hansen, O.; Vesborg, P. C. K.;

Chorkendorff, I. Back-Illuminated Si-Based Photoanode with Nickel Cobalt Oxide Catalytic

Protection Layer. ChemElectroChem 2016, 3, 1546-1552.

(18) Mei, B.; Permyakova, A. A.; Frydendal, R.; Bae, D.; Pedersen, T.; Malacrida, P.; Hansen,

O.; Stephens, I. E. L.; Vesborg, P. C. K.; Seger, B.; et al. Iron-Treated NiO as a Highly

Transparent p-Type Protection Layer for Efficient Si-Based Photoanodes. J. Phys. Chem. Lett.

2014, 5, 3456-3461.

(19) Hu, S.; Shaner, M. R.; Beardslee, J. A.; Lichterman, M.; Brunschwig, B. S.; Lewis, N. S.

Amorphous $\mathrm{TiO}_{2}$ Coatings Stabilize Si, GaAs, and GaP Photoanodes for Efficient Water

Oxidation. Science 2014, 344, 1005 LP-1009.

(20) Shaner, M. R.; Hu, S.; Sun, K.; Lewis, N. S. Stabilization of Si Microwire Arrays for

Solar-Driven $\mathrm{H}_{2} \mathrm{O}$ Oxidation to $\mathrm{O}_{2}(\mathrm{~g})$ in $1.0 \mathrm{M} \mathrm{KOH}(\mathrm{aq})$ Using Conformal Coatings of Amorphous $\mathrm{TiO}_{2}$. Energy Environ. Sci. 2015, 8, 203-207. 
(21) Sun, K.; Saadi, F. H.; Lichterman, M. F.; Hale, W. G.; Wang, H.-P.; Zhou, X.; Plymale, N. T.; Omelchenko, S. T.; He, J.-H.; Papadantonakis, K. M.; et al. Stable Solar-Driven Oxidation of Water by Semiconducting Photoanodes Protected by Transparent Catalytic Nickel Oxide Films. Proc. Natl. Acad. Sci. USA 2015, 112, 3612-3617.

(22) Sun, K.; McDowell, M. T.; Nielander, A. C.; Hu, S.; Shaner, M. R.; Yang, F.;

Brunschwig, B. S.; Lewis, N. S. Stable Solar-Driven Water Oxidation to $\mathrm{O}_{2}(\mathrm{~g})$ by Ni-OxideCoated Silicon Photoanodes. J. Phys. Chem. Lett. 2015, 6, 592-598.

(23) Sun, K.; Park, N.; Sun, Z.; Zhou, J.; Wang, J.; Pang, X.; Shen, S.; Noh, S. Y.; Jing, Y.; Jin, S.; et al. Nickel Oxide Functionalized Silicon for Efficient Photo-Oxidation of Water. Energy Environ. Sci. 2012, 5, 7872-7877.

(24) Sun, K.; Shen, S.; Cheung, J. S.; Pang, X.; Park, N.; Zhou, J.; Hu, Y.; Sun, Z.; Noh, S. Y.; Riley, C. T.; et al. Si Photoanode Protected by a Metal Modified ITO Layer with Ultrathin $\mathrm{NiO}_{\mathrm{x}}$ for Solar Water Oxidation. Phys. Chem. Chem. Phys. 2014, 16, 4612-4625.

(25) Reece, S. Y.; Hamel, J. A.; Sung, K.; Jarvi, T. D.; Esswein, A. J.; Pijpers, J. J. H.;

Nocera, D. G. Wireless Solar Water Splitting Using Silicon-Based Semiconductors and EarthAbundant Catalysts. Science 2011, 334, 645 LP-648.

(26) Hill, J. C.; Landers, A. T.; Switzer, J. A. An Electrodeposited Inhomogeneous MetalInsulator-Semiconductor Junction for Efficient Photoelectrochemical Water Oxidation. Nat. Mater. 2015, 14, 1150-1155.

(27) Yu, X.; Yang, P.; Chen, S.; Zhang, M.; Shi, G. NiFe Alloy Protected Silicon Photoanode for Efficient Water Splitting. Adv. Energy Mater. 2016, 1601805.

(28) Laskowski, F. A. L.; Nellist, M. R.; Venkatkarthick, R.; Boettcher, S. W. Junction Behavior of n-Si Photoanodes Protected by Thin Ni Elucidated from Dual Working Electrode 
Photoelectrochemistry. Energy Environ. Sci. 2017, DOI: 10.1039/c6ee03505a

(29) Medway, S. L.; Lucas, C. A.; Kowal, A.; Nichols, R. J.; Johnson, D. In Situ Studies of the Oxidation of Nickel Electrodes in Alkaline Solution. J. Electroanal. Chem. 2006, 587, 172181.

(30) Santinacci, L.; Diouf, M. W.; Barr, M. K. S.; Fabre, B.; Joanny, L.; Gouttefangeas, F.; Loget, G. Protected Light-Trapping Silicon by a Simple Structuring Process for SunlightAssisted Water Splitting. ACS Appl. Mater. Interfaces 2016, 8, 24810-24818. 


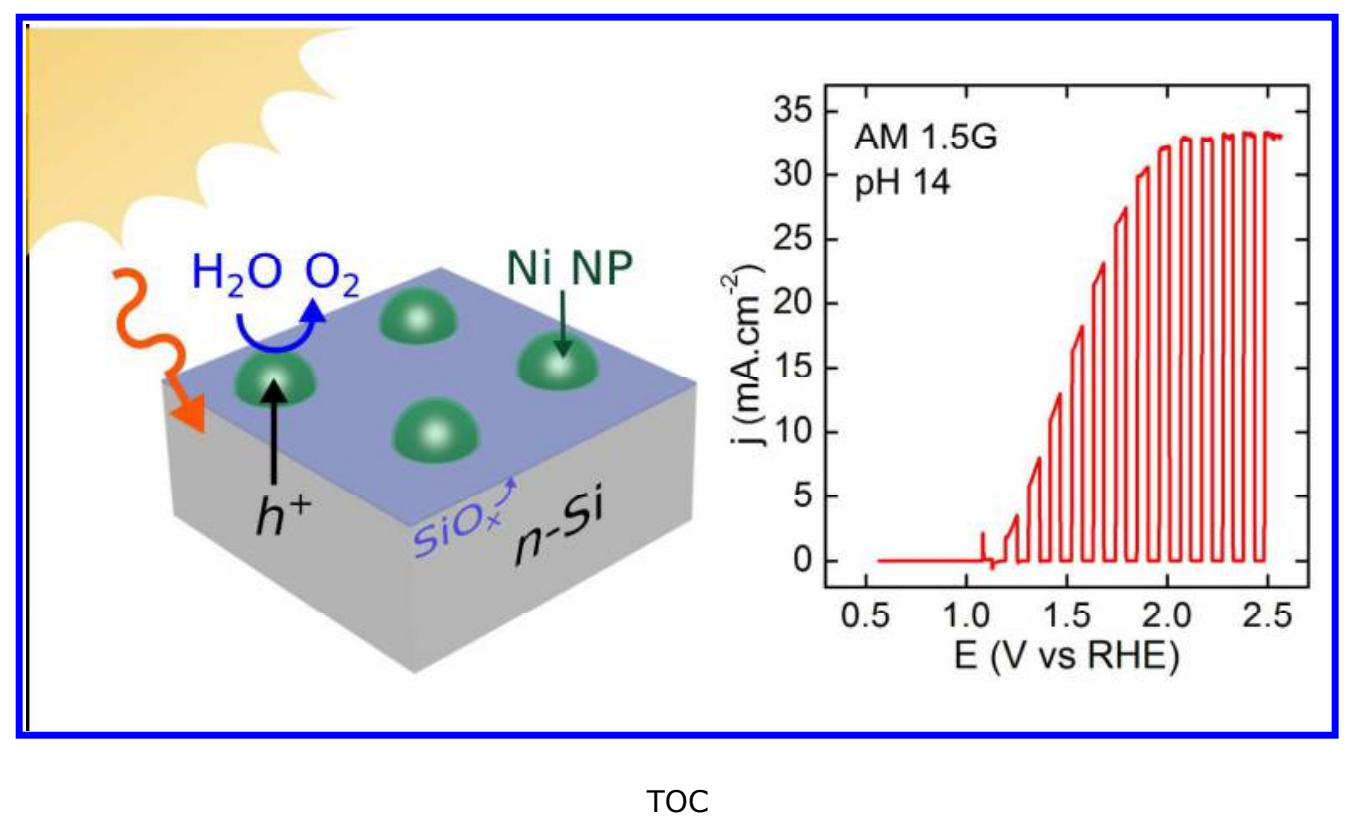

$1286 \times 697 \mathrm{~mm}(72 \times 72 \mathrm{DPI})$ 


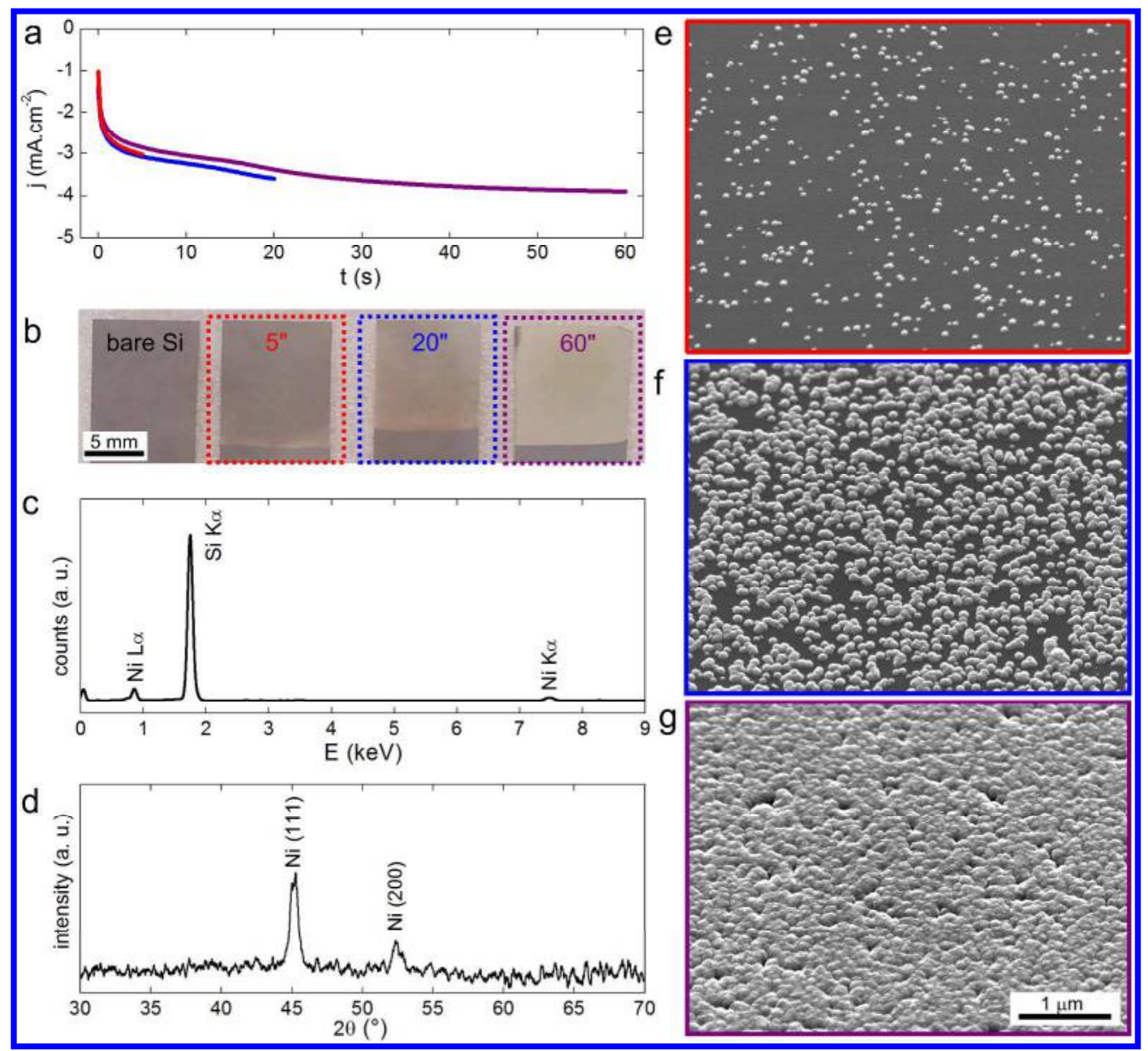

Figure 1. Characterization of the Ni-decorated surfaces. a) Chronoamperograms for Ni electrodeposition on hydrogenated n-Si. b) Photographs of bare and Ni-coated n-Si. c) EDS and d) XRD spectra of Ni-coated n-Si. e-g) SEM pictures showing the $\mathrm{Ni}$ deposits on $\mathrm{n}$-Si (the surfaces were tilted by $45^{\circ}$ ). In these panels, data depicted or framed in red, blue and purple correspond to the surfaces obtained for electrodeposition times of $5 \mathrm{~s}, 20 \mathrm{~s}$ and $60 \mathrm{~s}$, respectively.

$1426 \times 1315 \mathrm{~mm}(72 \times 72 \mathrm{DPI})$ 


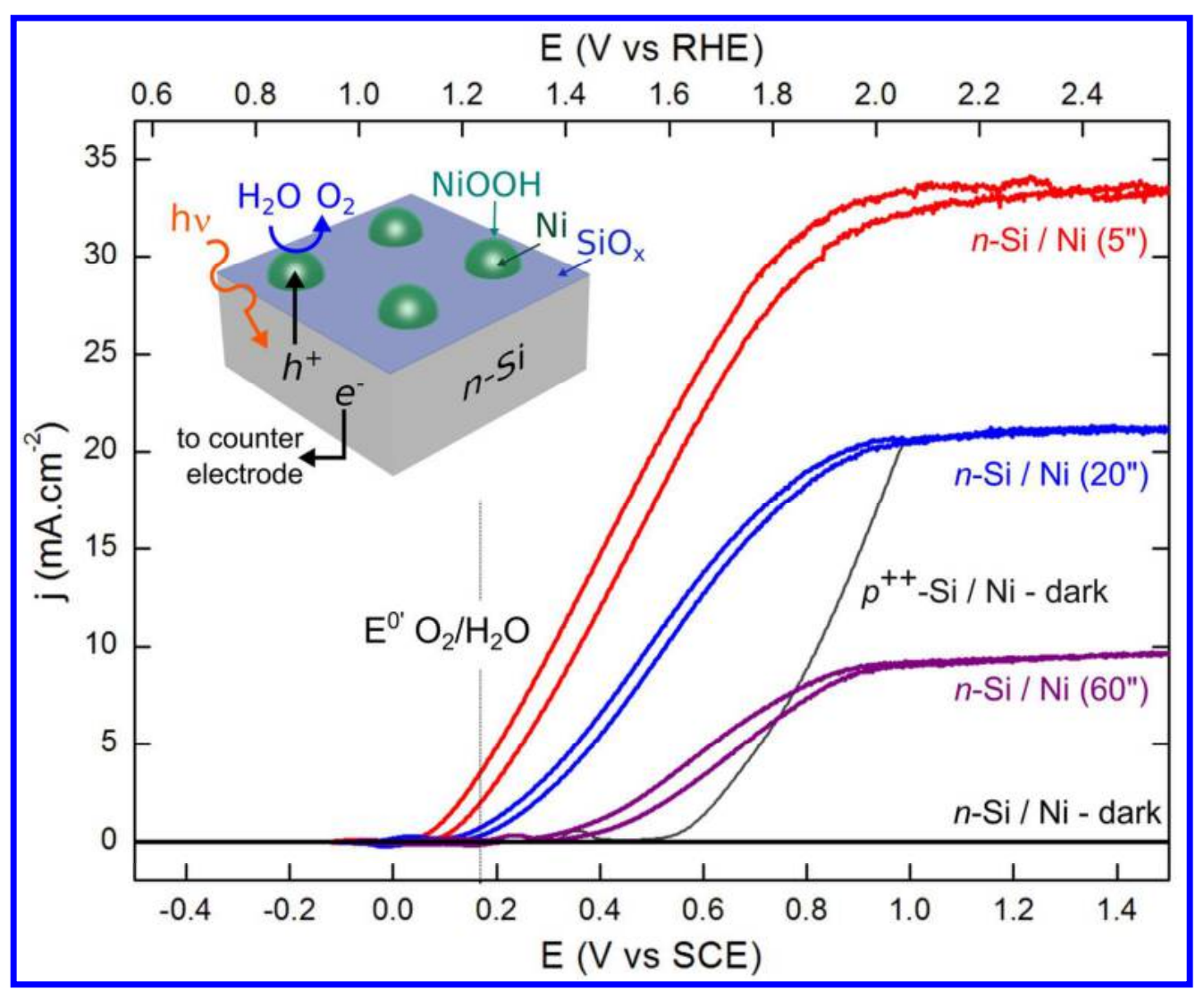

Figure 2. Photoelectrochemical water oxidation. CVs measured in the dark for $n-S i$ decorated with Ni NPs (thick black line) and $\mathrm{p}++-\mathrm{Si}$ coated with $\mathrm{Ni}$ (thin black line) and under illumination (AM $1.5 \mathrm{G}, 100 \mathrm{~mW} \mathrm{~cm}$ 2) for $\mathrm{n}-\mathrm{Si}$ coated with Ni for $5 \mathrm{~s}$ (red line), $20 \mathrm{~s}$ (blue line) and $60 \mathrm{~s}$ (purple line); all the curves were recorded in $1 \mathrm{M} \mathrm{NaOH}$ at a sweep rate of $20 \mathrm{mV} \mathrm{s}$-1. Inset: scheme of the surface under illumination.

$65 \times 54 \mathrm{~mm}(600 \times 600 \mathrm{DPI})$ 


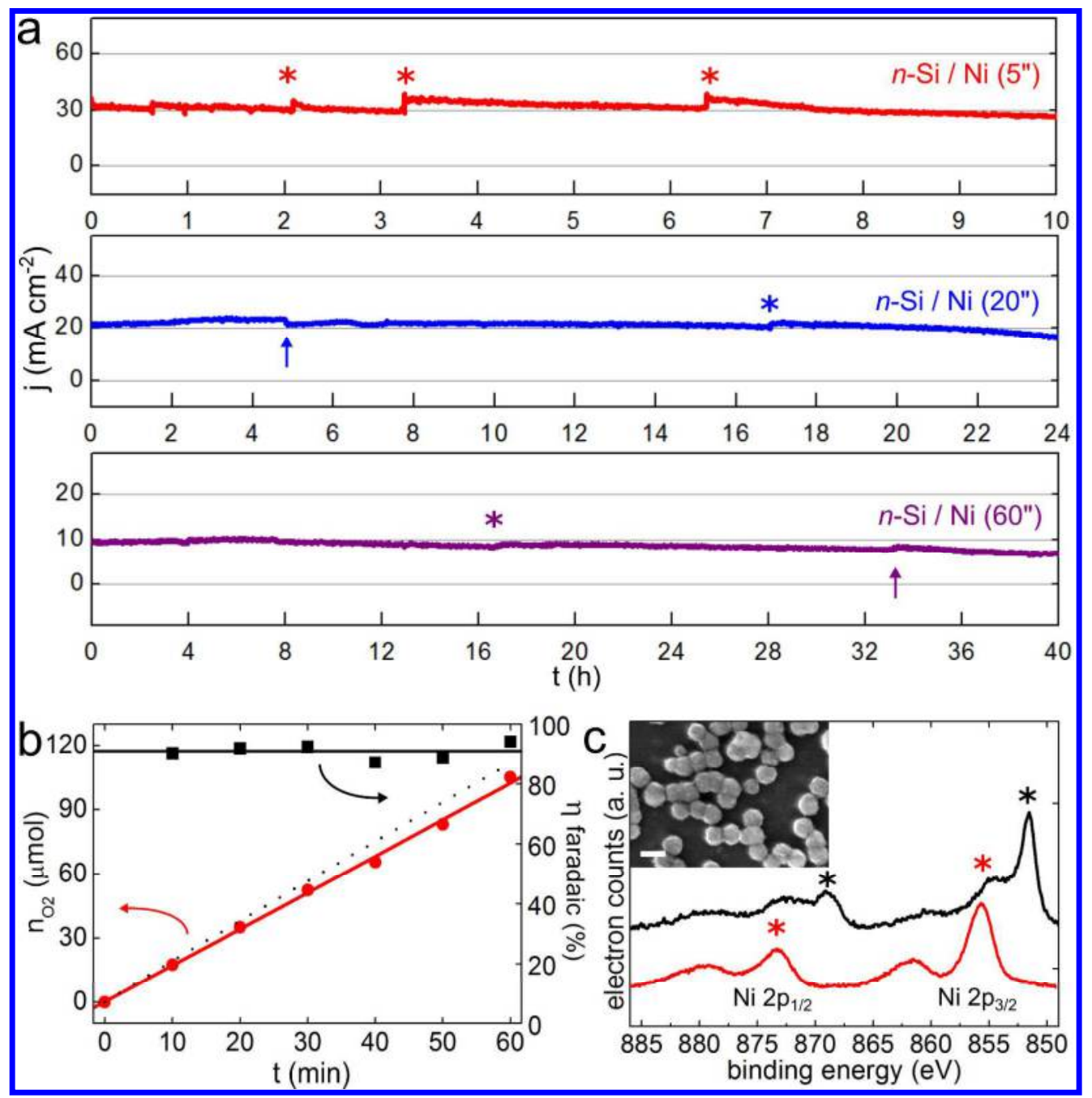

Figure 3. Stability and faradaic efficiency of the photoanodes. a) CAs obtained during prolonged photoelectrolysis in $1 \mathrm{M} \mathrm{NaOH}$ under AM $1.5 \mathrm{G}$ illumination at $+1 \mathrm{~V}$ vs SCE for $\mathrm{n}-\mathrm{Si}$ surfaces coated with $\mathrm{Ni}$ that was electrodeposited for $5 \mathrm{~s}$ (red), $20 \mathrm{~s}$ (blue) and $60 \mathrm{~s}$ (purple). The asterisks indicate when bubbles were removed from the surface, arrows indicate when the electrolysis was stopped and the photoelectrodes were dried and stored overnight. b) Number of moles of $\mathrm{O} 2$ produced (red disks are experimental data and the red line is a linear fit) during a preparative electrolysis at $+1 \mathrm{~V}$ vs SCE using a n-Si surface coated with $\mathrm{Ni}$ for $5 \mathrm{~s}$ (see SI for more details). The black dotted line is the theoretical amount of O2, the black squares and the black line are the faradaic efficiencies and its average value, respectively. c) XPS spectra of the Ni

$2 \mathrm{p}$ region for the $\mathrm{n}$-Si surface coated with $\mathrm{Ni}$ for $20 \mathrm{~s}$; after preparation (black line) and after $\approx 25 \mathrm{~h}$ of electrolysis (red line). The black asterisks indicate NiO peaks and the red asterisks indicate $\mathrm{Ni}$ oxides peaks

(more information on the spectra is provided in the SI). Inset: SEM picture showing the corresponding surface after electrolysis, the scale bar corresponds to $100 \mathrm{~nm}$. 